\title{
Novel Wavelet-Fuzzy Based Indirect Field Oriented Control of Induction Motor Drives
}

\author{
Febin Daya J. L. ${ }^{\dagger}$, Subbiah V.*, Atif Iqbal**, and Sanjeevikumar Padmanaban ${ }^{* * *}$ \\ $\dagger,{ }^{* * *}$ School of Electrical Eng., VIT University-Chennai Campus, India \\ *Dept. of Electrical and Electronics Eng., P.S.G College of Technology, Coimbatore, India \\ *** Dept. of Electrical Eng., Qatar University, Doha, Qatar
}

\begin{abstract}
This paper presents a wavelet-fuzzy based controller for indirect field oriented control of three-phase induction motor drives. The discrete wavelet transform is used to decompose the error between the actual speed and the command speed of the induction motor drive into different frequency components. The transformed error coefficients along with the scaling gains are used for generating the control component of the motor. Self-tuning fuzzy logic is used for online tuning of the scaling gains of the controller. The proposed controller has the ability to meet the speed tracking requirements in the closed loop system. The complete indirect field oriented control scheme incorporating the proposed wavelet-fuzzy based controller is investigated theoretically and simulated under various dynamic operating conditions. The simulation results are compared with a conventional proportional integral controller and a fuzzy based controller. The speed control scheme incorporating the proposed controller is implemented in real time using a digital processor control board. Simulation and experimental results validate the effectiveness of the proposed controller.
\end{abstract}

Key words: Discrete wavelet transform, Field oriented control, Fuzzy logic control, Induction motor drive, Robustness

\section{INTRODUCTION}

Induction motors are the most widely used motors for industrial control, automation and commercial appliances. They are highly reliable, simple in construction, relatively low in cost and have modest maintenance requirements. Induction motors are complex due to the non-linearity of their parameters. In particular, the rotor resistance and hence the rotor time constant vary with the operating conditions. Hence, their control remains a challenging problem for high performance applications. However, with the apparition of field orientation control (FOC), induction motor drives are becoming a major candidate in high-performance motion control applications. The decoupling effect of the torque and flux dynamics leads to independent control of the torque and flux as in a separately excited DC motor. Though attractive, the FOC methods suffer from the disadvantages of sensitivity to motor parameter variations such as the rotor time constant and incorrect flux

Manuscript received Nov. 23, 2012; revised Jan. 3, 2013

Recommended for publication by Associate Editor Marian P. Kazmierkowski.

${ }^{\dagger}$ Corresponding Author: febinresearch@gmail.com

Tel: +91-44-3993-1261, Fax: +91-44-3993-2555, VIT University-Chennai Campus

*Dept. of Electrical and Electronics Eng., P.S.G College of Tech., India

*** Dept. of Electrical Eng., Qatar University, Qatar

${ }^{* * *}$ School of Electrical Eng., VIT University-Chennai Campus, India measurements.

The variable speed issues of motors are traditionally handled by conventional controllers such as proportional integral (PI) and proportional integral derivative (PID) controllers. Even though they are simple, these controllers are very sensitive to parameter variations, changes in load, changes in command speed and other uncertainties. Moreover, the performance of these controllers varies with the operating conditions. They have difficulty in dealing with dynamic speed tracking, parameter variations and load disturbances since the controllers' gain values are fixed. The performance of the speed control system also depends on the accuracy of the slip calculation. Unfortunately, the slip calculation depends on the rotor time constant, which varies continuously according to the operational conditions. Thus the control parameters of these controllers are not adaptive. Many solutions have been proposed to overcome the problems mentioned above, such as model reference adaptive control, sliding-mode control, variable structure control, self-tuning PI control, etc. The design techniques for all of the above control techniques depend on an exact mathematical model of the system. However, it is often difficult to develop an accurate system mathematical model due to unknown load variations, unknown and unavoidable parameter variations like saturation, temperature variations, and system disturbances [12]. 


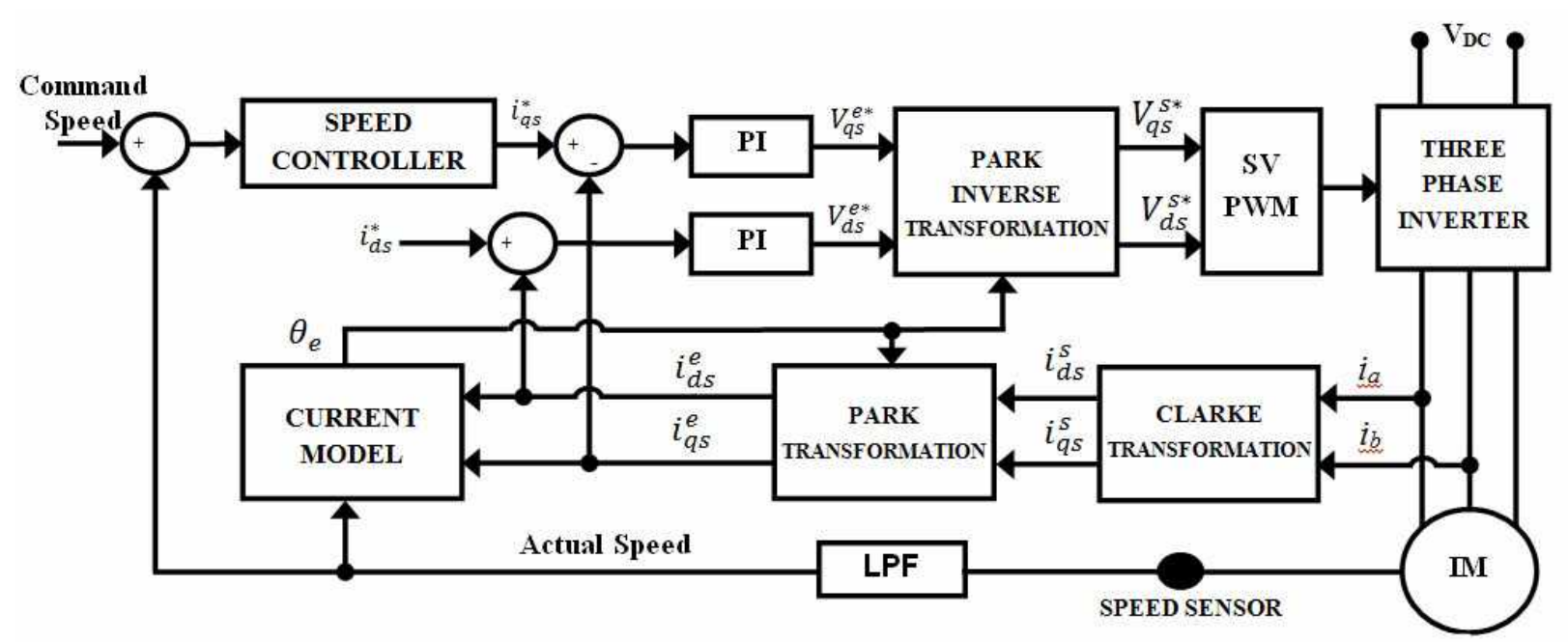

Fig. 1. Configuration of Indirect Field Oriented Control of Induction motor drive.

In the past decade, intensive research has been done on the design and implementation of fuzzy logic controllers (FLC), neural network controllers (NNC) and hybrid controllers for high performance applications of induction motor drives [15].

The FLC is the simplest of all the intelligent controllers for induction motor speed control applications [2]. However, FLCs have difficulties in determining appropriate control laws and tuning the parameters of the membership function according to changes in the system. The NNC on the other hand, has the ability to adapt itself to changes in the control environment using the system input and output [1]. It does not require complicated control theories or an exact model of the system. However, NNC synthesis requires a design of the control structure which includes selecting the neural network structure, weight coefficients and activation function. The selection of the neural structure as the initial step is done by the trial and error method, since there is no proper procedure for this [19]. The complexity of the selected neural network structure is a compromise between high quality control robustness and the possibility of control algorithm calculation in real time. Hybrid controllers, like the neuro fuzzy controller, implement the high level learning and low computation power of neural networks to fuzzy control systems. However, the problem of finding a well defined procedure for finding an optimum network topology for induction motor drives still remains as a challenge [15].

Recent literature has reported work on the use of time frequency localization of the wavelet transform in the speed control of electric drives [2]. The wavelet transform has the ability to decompose wide band signals into time and frequency localized sub bands. Wai has proposed a robust wavelet neural network (WNN) controller to control the rotor position of an induction motor [1]. Wai et al. have implemented an adaptive observation system and a WNN control system for achieving favorable decoupling control and high-precision position tracking performance of an induction motor drive [2]. Lin et al. have developed an adaptive WNN control system to control the position of a permanent magnet linear synchronous motor servo drive system to track periodic reference trajectories [3]. Wai and Chang have designed and implemented a robust WNN sliding-mode control system for an indirect field-oriented induction servo motor drive to track periodic commands [4]. Shanlin and Yuzhe proposed a novel flux and torque estimation method based on a wavelet network, for an induction motor control system [5]. Khan and Rahman [6], [7] implemented a wavelet based multiresolution PID controller in real time for precise speed control of an interior PMSM drive. Yousef et al. [8] have developed wavelet network based controllers for motion control of a DC motor. Pravez et al. [9] have carried out work on a wavelet based PID controller for brushless dc servo motor speed control. Azadi et al. have developed a wavenet based control for vector control of a permanent magnet synchronous motor (PMSM) drive [10]. However, this system lacks stability. Saleh et al. [11] have done an analysis and real time testing of wavelet modulated inverters for single phase induction motors.

Based on the above discussion it can be concluded that there is a recent trend in the research work on the application of wavelet transforms along with intelligent techniques such as neural networks and fuzzy logic control for robust speed control of electric drives. Many studies have been reported on combining the advantages of wavelet transforms and neural networks for high performance applications of induction motor drives [2]-[8]. However, very few studies have been done on combining the advantages of wavelet transforms and fuzzy logic for speed control of induction motor drives. Therefore, an effort should be made to develop a wavelet-fuzzy based intelligent controller for speed control of induction motor drives. This work presents a novel wavelet fuzzy based self-tuning controller for robust speed control of 
indirect field oriented induction motor drives. The proposed control scheme has been evaluated through simulation and experimental investigations and it has been compared with both conventional PID and fuzzy controllers. The proposed controller is suitable for applications where the induction motor is operates under uncertain conditions and prior information about the motor is limited. The proposed speed control scheme produced better robustness in terms of peak overshoot, settling time. It also produced less root mean square error (RSME).

\section{MOTOR DYNAMICS AND CONTROL STRUCTURE}

The configuration of the speed control scheme investigated in this study is shown in Fig. 1. It applies indirect field oriented control (IFOC) to a three phase squirrel cage induction motor by means of a space vector pulse width modulation (SVPWM). The dynamic model of a three phase squirrel cage IM in the $d^{e}-q^{e}$ synchronously rotating reference frame can be found in several papers [12], [13]. IFOC achieves an ideal torque and flux decoupling by means of $\mathrm{d}-\mathrm{q}$ axis transformations and two proportional - integral (PI) controllers.

The command speed of the motor is compared with the actual speed to generate the error speed. The error speed is given as an input to the speed controller. The speed controller generates the command torque component current and thus the q-axis command current $\mathrm{i}_{\mathrm{qs}}^{*}$ for the induction motor drive. The command currents are compared with their respective $\mathrm{d}$-axis and q-axis currents, which are generated by the transformation of the stator currents. The respective errors generate the voltage command signals $\mathrm{v}_{\mathrm{ds}}^{*}$ and $\mathrm{v}_{\mathrm{qs}}^{*}$ through the PI controllers. These voltages are converted into stationary reference frame voltages and are used for generating the switching signals for the SVPWM. The outputs of the SVPWM are the signals that drive the inverter. The current model generates the rotor flux position and hence the slip speed.

\section{WAVELET TRANSFORM FOR SPEED CONTROL}

The wavelet transform of a signal is another form of representing signal. It does not change the information content of the signal. The wavelet transform provides a time-frequency representation of the signal [21]. The wavelet transform can be used to perform a multiresolution analysis (MRA), which can extract and localize the frequency components of a signal at a time. The MRA represents a function as a successive limit of approximations at different stages. Each stage consists of an approximate version and a detail version. The discrete wavelet transform (DWT) of the signal $\mathrm{x}(\mathrm{t})$ can be written as:

$$
\mathrm{WT}_{\mathrm{m}, \mathrm{n}} \mathrm{x}(\mathrm{t})=\int_{-\infty}^{\infty} \mathrm{x}(\mathrm{t}) \Psi_{\mathrm{m}, \mathrm{n}}^{*}(\mathrm{t}) \mathrm{dt}
$$

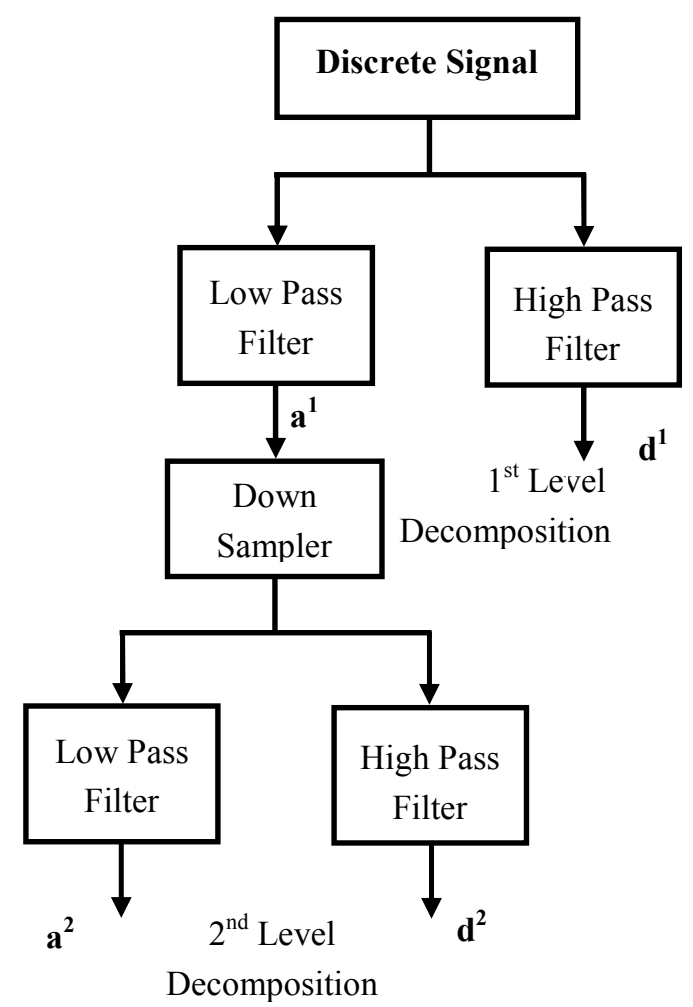

Fig. 2. DWT Decomposition Tree.

where $\Psi^{*}(\mathrm{t})$ is the wavelet function and $\mathrm{m}$ and $\mathrm{n}$ represent the dilation and the translational parameters.

The DWT is realized through cascaded stages of low pass (g) and high pass (h) filters, followed by down sampling, which performs frequency dilation. The output from the low pass filter is the approximation coefficient of the signal at the first level of decomposition represented by $\mathrm{a}^{1}$. The output from the high pass filter is the detailed coefficient of the signal at the first level of decomposition represented by $\mathrm{d}^{1}$. The coefficients $a^{1}$ and $d^{1}$ constitute the first level of decomposition. They can be mathematically represented as [6]:

$$
\begin{aligned}
& a^{1}[n]=\sum_{k=0}^{N-1} g[k] x[n-k] \\
& d^{1}[n]=\sum_{k=0}^{N-1} h[k] x[n-k]
\end{aligned}
$$

The approximation coefficients $a^{1}$ at the first level of decomposition are given as the input to another pair of filters after being down sampled by two. The second level low pass and high pass filters generate the second level approximation and detailed coefficients of the length $N / 2$. This can be mathematically represented as:

$$
\begin{aligned}
& \mathrm{a}^{2}[\mathrm{n}]=\sum_{\mathrm{k}=0}^{\mathrm{N} / 2-1} \mathrm{~g}[\mathrm{k}] \mathrm{a}^{1}[2 \mathrm{n}-\mathrm{k}] \\
& \mathrm{d}^{2}[\mathrm{n}]=\sum_{\mathrm{k}=0}^{\mathrm{N} / 2-1} \mathrm{~h}[\mathrm{k}] \mathrm{a}^{1}[2 \mathrm{n}-\mathrm{k}]
\end{aligned}
$$




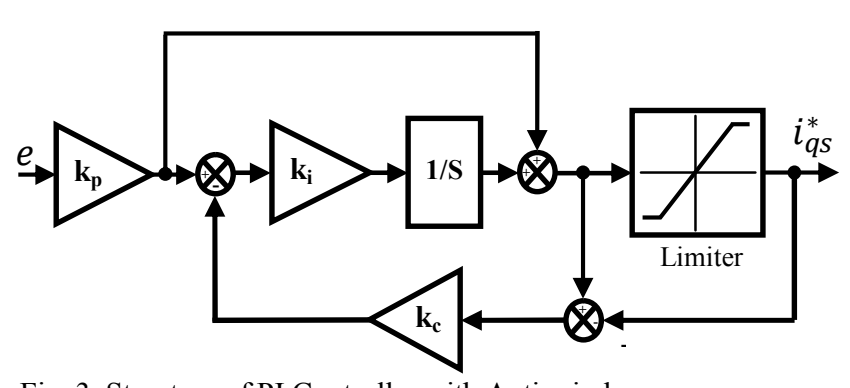

Fig. 3. Structure of PI Controller with Anti-windup.

The filtering and down sampling process continues until the desired level is reached. The DWT decomposition tree is shown in Fig 2.

\section{SPEed CONTROLler Design}

\section{A. PI Controller}

The PI controller gains are initially tuned using the bode plot technique. The gain margin and the phase margin of the designed PI controller are within the bandwidth limits having a gain margin and a phase margin of $2.2 \mathrm{db}$ and $30^{\circ}$, respectively to meet the stability criteria. It is subsequently tuned using simulations in order to achieve a satisfactory response.

The anti-windup correction is used to avoid saturation of the controller. The structure of the controller is shown in Fig 3. The choice of the limit gain $\mathrm{K}_{\mathrm{c}}$ of the PI controller with the anti-windup depends on the steady state value of the controller output $\mathrm{i}_{\mathrm{qs}}^{*}$. The limit gain $\mathrm{K}_{\mathrm{c}}$ has to be kept high, so that the controller output will come out of saturation quickly when the error input to the controller is reversed. Usually the limit gain $\mathrm{K}_{\mathrm{c}}$ is selected as $1 / \mathrm{K}_{\mathrm{p}}$. The same method has been used in the controller design and it makes the design of a PI controller with anti-windup simple.

\section{B. Wavelet Based Speed Controller}

All physical systems are subjected to some type of extraneous signal or noise during operation. Therefore, in the design of a control system, consideration has to be made to see to it that the system provides greater insensitivity to noise and disturbance. In practice, the disturbance and commands are often low frequency signals, while sensor noises are high frequency signals. This makes it difficult to minimize the effects of these uncertainties simultaneously. Under these conditions, the wavelet based controller can perform extremely well by discriminating the signals into different frequency bands.

In a conventional PID controller, the control output $\mathrm{u}$ is generated making use of the error signal $\mathrm{e}$ and further processing it. The output of the PID controller is given by:

$$
\mathrm{u}=\mathrm{k}_{\mathrm{p}} \mathrm{e}+\mathrm{k}_{\mathrm{i}} \int \mathrm{e} \mathrm{dt}+\mathrm{k}_{\mathrm{d}} \frac{\mathrm{de}}{\mathrm{dt}}
$$

where $\mathrm{k}_{\mathrm{p}}, \mathrm{k}_{\mathrm{i}}$ and $\mathrm{k}_{\mathrm{d}}$ are the proportional, integral and derivative gain constants, respectively. These gain constants acts on the error signal as shown in (6). In terms of frequency information, the proportional and the integral terms capture the low frequency information of the error signal which corresponds to the steady state performance of the controller, and the derivative term captures the high frequency information of the error signal which corresponds to the transient performance of the controller.

The DWT performs the same operation of decomposing a signal into low frequency (detail) and high frequency (approximate) coefficients at different levels of resolution. This feature of the wavelet transform can be made use of in developing a wavelet based controller for the expected control actions. The control signal for the wavelet based controller can be calculated from the detail and approximate coefficients of the wavelet transform as [20]:

$$
\mathrm{u}_{\mathrm{w}}=\mathrm{k}_{\mathrm{d}^{1}} \mathrm{e}_{\mathrm{d}^{1}}+\mathrm{k}_{\mathrm{d}^{2}} \mathrm{e}_{\mathrm{d}^{2}}+\cdots+\mathrm{k}_{\mathrm{d}^{\mathrm{N}}} \mathrm{e}_{\mathrm{d}^{\mathrm{N}}}+\mathrm{k}_{\mathrm{a}^{\mathrm{N}}} \mathrm{e}_{\mathrm{a}^{\mathrm{N}}}
$$

where $\mathrm{e}_{\mathrm{d}^{1}}, \mathrm{e}_{\mathrm{d}^{2}}, \ldots, \mathrm{e}_{\mathrm{d}^{\mathrm{N}}}$ corresponds to the detail components of the error signal and $e_{a^{N}}$ is the approximate component of the error signal. The gains $\mathrm{k}_{\mathrm{d}^{1}}, \mathrm{k}_{\mathrm{d}^{2}}, \ldots, \mathrm{k}_{\mathrm{d}^{\mathrm{N}}}$ are used to tune the high and medium frequency components of the error signal. The gain $\mathrm{k}_{\mathrm{a}^{\mathrm{N}}}$ is used for tuning the low frequency component of the error signal.

While dealing with motor drives, the command and disturbance are low frequency signals. The sensor noises are high frequency signals. Therefore, the gain which corresponds to the low frequency components of the error signal can be used to improve the disturbance rejection of the system. The gain which corresponds to the medium frequency components of the error signal adds damping to the system and can be used to improve the transient response. The gain which corresponds to the high frequency components of the error signal can be set to minimum to eliminate the effect of noise on the system.

\section{Optimum Wavelet Function and Level of Decomposition}

Before applying the wavelet transform it is necessary to select an appropriate wavelet function and an optimum level of decomposition. Different methods are available in the literature, but the minimum description length (MDL) data criterion is best suited to select the best wavelet function [14]. According to the MDL criterion, the best model within the group model of models will have the shortest description of the data model itself. The MDL criterion can be defined as [14]:

$$
\begin{aligned}
& \operatorname{MDL}(\mathrm{k}, \mathrm{n})=\min \left\{\frac{3}{2} \mathrm{k} \log \mathrm{N}+\frac{\mathrm{N}}{2} \log \left\|\widetilde{\alpha}_{\mathrm{n}}-\alpha_{\mathrm{n}}^{(\mathrm{k})}\right\|^{2}\right\} \\
& 0 \leq \mathrm{k}<\mathrm{N} ; \quad 1 \leq \mathrm{n} \leq \mathrm{M}
\end{aligned}
$$




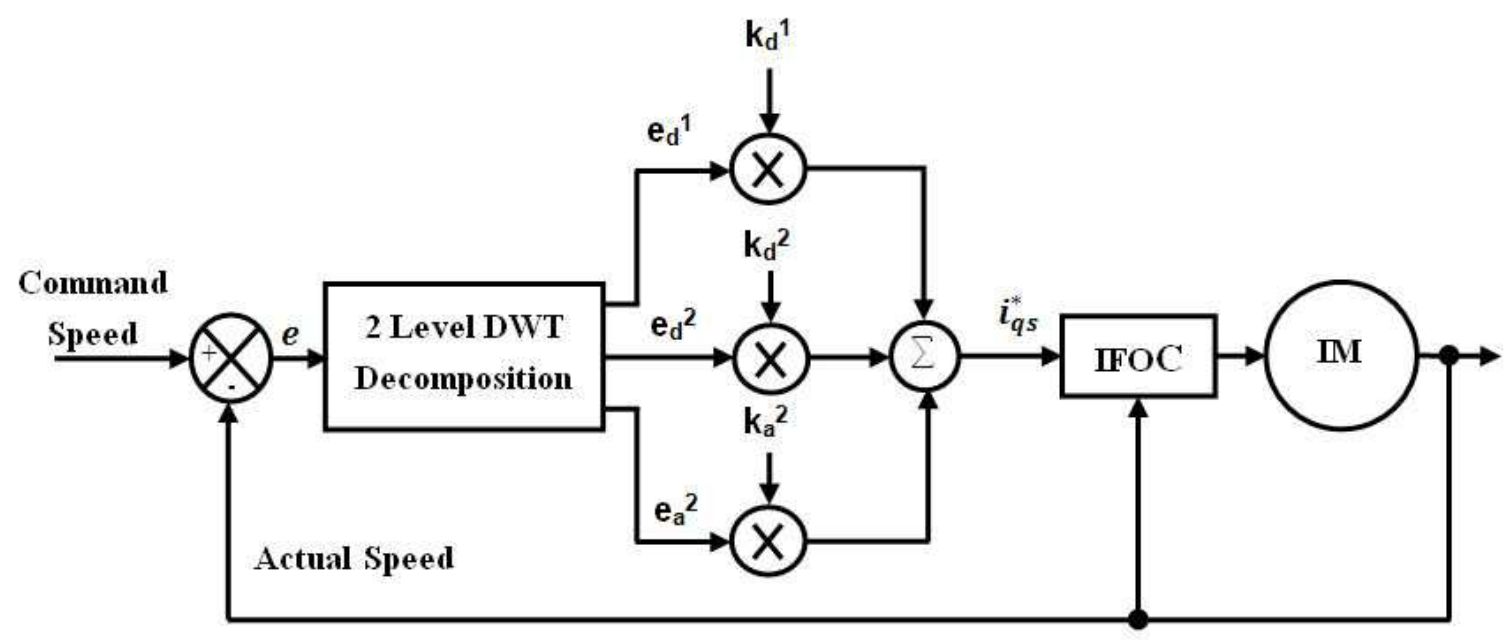

Fig. 4. Schematic of the wavelet based speed controller for IFOC of Induction motor drive

where $\mathrm{k}$ and $\mathrm{n}$ are the indices. The integers $\mathrm{N}$ and $\mathrm{M}$ denote the length of the signal and the wavelet filters used, respectively. $\widetilde{\alpha}_{n}$ is the vector of the wavelet transformed coefficients of the signal using the wavelet filter and $\alpha_{\mathrm{n}}^{(\mathrm{k})}=\Theta^{\mathrm{k}} \widetilde{\alpha}_{\mathrm{n}}$ denotes the vector containing $\mathrm{k}$ non-zero elements. The threshold parameter $\Theta^{\mathrm{k}}$ keeps $\mathrm{k}$ number of the largest elements of $\widetilde{\alpha}_{n}$ and sets all of the other elements to zero. The number of coefficients $\mathrm{k}$, for which the MDL criterion gives the minimum value is considered to be the optimum one. In proposed studies, all of the wavelets which are available in the simulation tool are tested using the MDL criterion to select the best suitable wavelet. The "db4" wavelet, which belongs to the orthogonal Daubechies family, is chosen as the optimum wavelet for the proposed wavelet-fuzzy based control of induction motor drives.

The Shannon entropy based criterion is best suited to find the optimum level of decomposition of the signal for motor drive applications. The entropy of a signal $x(n)$ of length $N$ can be represented as [14]:

$$
H(x)=-\sum_{n=0}^{N-1}|x(n)|^{2} b g|x(n)|^{2}
$$

The entropy is calculated at every level of decomposition for both the approximate and the detailed coefficients of the transformed signal in order to find the optimum level of decomposition. According to the Shannon entropy based criterion, the entropy of the signal at a new level (p) is higher than the previous level ( $p-1)$ if:

$$
H(x)_{p} \geq H(x)_{p-1}
$$

then the decomposition of the signal can be stopped at level $(p-1)$, and $(p-1)$ represents the optimum level decomposition. In the proposed work, the entropy values are calculated for the speed error signal after decomposing it using the db4 wavelet which is selected as the optimum wavelet function. The optimum level of decomposition is found to be two for the proposed wavelet fuzzy based controller for speed control of an induction motor drive.

The schematic of the wavelet based speed control of an induction motor drive is shown in Fig 4. The error signal is decomposed up to the second level of decomposition using the DWT. The decomposed signal is multiplied by the corresponding gain values and summed up together to generate the command signal $\mathrm{u}_{\mathrm{w}}$ as represented by equation (11).

$$
u_{w}=k_{d^{1}} e_{d^{1}}+k_{d^{2}} e_{d^{2}}+k_{a^{2}} e_{a^{2}}
$$

The command $\mathrm{u}_{\mathrm{w}}$ is used as the torque component current signal $\mathrm{i}_{\mathrm{qs}}^{*}$ for the indirect field oriented control of the induction motor drive. The gain $\mathrm{k}_{\mathrm{a}^{2}}$ which corresponds to the low frequency components of the error signal can be kept high in order to improve the disturbance rejection and settling time of the induction motor drive. The gain $\mathrm{k}_{\mathrm{d}^{2}}$ represents the medium frequency components of the error signal and it can be used to adjust the steady state behavior of the system. The gain $\mathrm{k}_{\mathrm{d}^{2}}$ can be kept high during the steady state operating region so as to reduce the steady state error. Similarly the gain $\mathrm{k}_{\mathrm{d}^{1}}$ which corresponds to the high frequency components of the error signal can be used to improve the transient response and reduce the overshoot of the drive system in order to produce smooth control of the induction motor drive. The gain $\mathrm{k}_{\mathrm{d}^{1}}$ can be used during the transient period, to achieve smooth control performance of the induction motor drive.

The scaling gains of the wavelet based speed controller have been selected by the trial and error method. However, the scaling gains have significant effects on the performance 


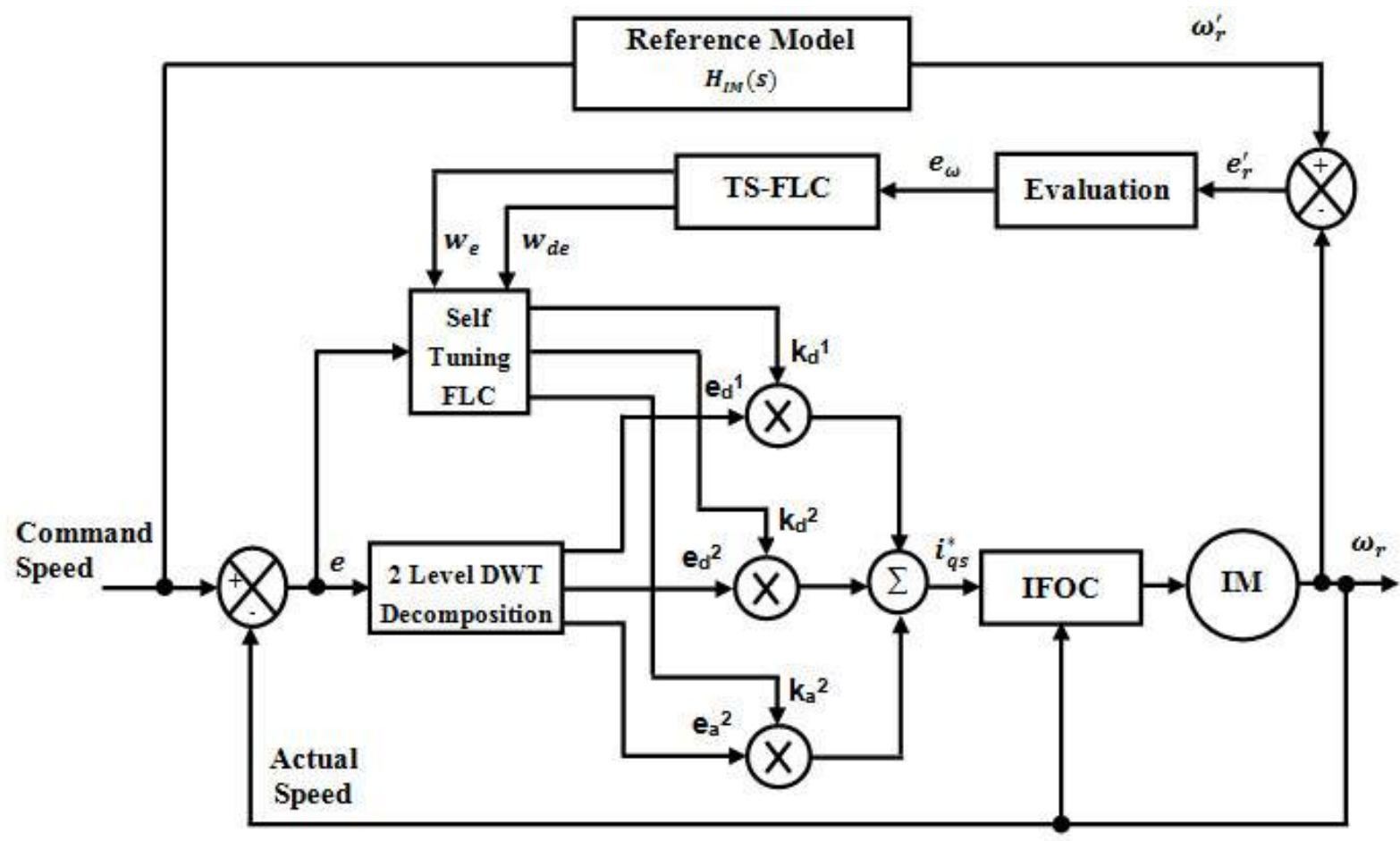

Fig. 5.Schematic of the wavelet-fuzzy based self tuning controller for IFOC of Induction motor drive.

of the wavelet based speed controller. Therefore, a proper procedure has to be adopted for calculating and updating the scaling gains of the wavelet based speed controller. A self-tuning fuzzy logic algorithm has been proposed for updating the scaling gains of the wavelet fuzzy based speed controller.

\section{WAVELET-FUZZY BASED CONTROLLER}

The schematic of the wavelet-fuzzy based self-tuning controller is shown in Fig 5. The self-tuning mechanism consists of a performance model, an evaluation block and a fuzzy logic control (FLC) block [15]. The reference model defines the desired dynamic performance of the motor drive. It is selected based on the maximum performance of the drive and to avoid excessive control action. For the IFOC of the induction motor, the reference model can be approximated by a second order system. The second order model is obtained from the procedure used in [16] and the constants a and $b$ are adjusted to meet the specific requirements of the induction motor investigated in the proposed work. The constants a and $\mathrm{b}$ are calculated as 47,000 and 180 , respectively.

$$
H_{m}(s)=\frac{a}{s^{2}+b s+a}
$$

The actual speed of the motor $\omega_{r}$ is compared with the output from the reference model $\omega_{\mathrm{r}}^{\prime}$, to generate the speed signal $\mathrm{e}_{\mathrm{r}}^{\prime}$, which is the difference between $\omega_{\mathrm{r}}$ and $\omega_{\mathrm{r}}^{\prime}$. This error signal is given as an input to the evaluation block. The evaluation block is designed in such a way that, if the error signal is within $+1 \mathrm{rad} / \mathrm{sec}$, the self-tuning mechanism will not operate. If the error $e_{r}^{\prime}$ exceeds the specific range of \pm 1 $\mathrm{rad} / \mathrm{sec}$, the evaluation block generates the tuning error $e_{\omega}$ which is given as an input to the Takagi Sugeno-fuzzy logic control (TS-FLC) block. The TS-FLC operates on this error signal to generate the online weight values $w_{e}$ and $w_{d e}$. These weight values are used to generate the scaling factors $n_{e}(k)$ and $n_{d e}(k)$ of the self tuning FLC. The scaling factors are generated at each step as:

$$
\begin{aligned}
n_{e}(k) & =n_{e}(k-1)\left[\alpha w_{e}(k)\right] \\
n_{d e}(k) & =n_{d e}(k-1)\left[\beta w_{d e}(k)\right]
\end{aligned}
$$

where $\alpha$ and $\beta$ are weight constants. The value of $\alpha$ is taken as 0.7 and $\beta$ is taken as 0.4 . The self tuning FLC operates on the actual error speed e and thee scaling factors to generate the scaling gains $\mathrm{k}_{\mathrm{d}^{1}}, \mathrm{k}_{\mathrm{d}^{2}}$ and $\mathrm{k}_{\mathrm{a}^{2}}$, which are used to tune the high, medium and low frequency components of the error signal $\mathrm{e}_{\mathrm{d}^{1}}, \mathrm{e}_{\mathrm{d}^{2}}$ and $\mathrm{e}_{\mathrm{a}^{2}}$, respectively.

The structure of the self-tuning FLC block is shown in Fig 6. The inputs are the speed error $\mathrm{e}(\mathrm{k})$, which is the difference between the command speed and the actual speed, and the change in error $\mathrm{de}(\mathrm{k}) . \mathrm{w}_{\mathrm{e}}$ and $\mathrm{w}_{\mathrm{de}}$ are the weight values obtained from the TS-FLC block. These weight values are varied online to tune the FLC block. The basic FLC block consists of a fuzzy interface (Fuzzification), fuzzy rules (Rule Base), a fuzzy inference (Inference Machine) and a defuzzification interface (Defuzzification). The input and 


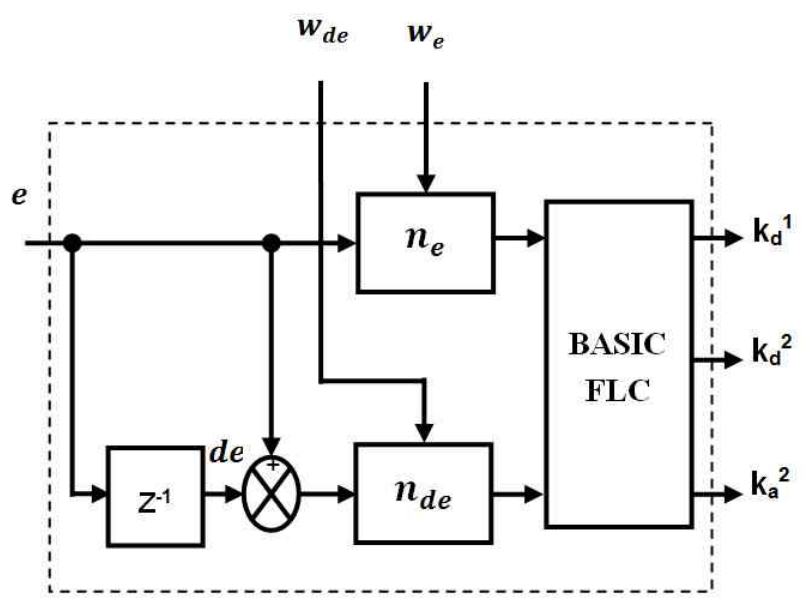

Fig. 6. Structure of Self-Tuning FLC Block.

TABLE I

FUZZY LOOK UP TABLE

\begin{tabular}{|c|l|l|l|l|l|}
\hline $\begin{array}{r}\text { e } \\
\text { de }\end{array}$ & NB & NM & ZE & PB & PM \\
\hline NB & NB & NB & NB & NM & ZE \\
\hline NM & NB & NB & NM & ZE & PM \\
\hline ZE & NB & NM & ZE & PM & PB \\
\hline PM & NM & ZE & PM & PB & PB \\
\hline PB & ZE & PM & PB & PB & PB \\
\hline
\end{tabular}

output variables are fuzzified using five membership functions normalized between +1 and -1 . The range of the input and output variables can be changed by altering the scaling factors of $n_{e}(k)$ and $n_{d e}(k)$ of the self-tuning fuzzy logic controller. The centroid method of defuzzification is used to convert the fuzzy values in to crisp values. The weight values of the self-tuning fuzzy logic are generated with five membership functions and 25 rules, using the TS-FLC block.

The number of membership functions can be increased to seven with 49 rules. However, this increases the computational burden and there is no significant improvement in the performance of the induction motor drive. The computation is faster when it is done with three membership functions and 9 rules. However, when this is compared with five membership functions and 25 rules, the performance is poor in terms of higher overshoot and longer settling time.

In the design of the rule base, the look up table is created offline, using data obtained during simulations under different operating conditions such as sudden changes in the command speed, load torque disturbances and changes in the stator resistance. The fuzzy look up table is given in Table I.

The scaling factors are updated only when the error $e_{r}^{\prime}$ is greater than the rad/sec. The tuning of the FLC is performed according to a simple predefined performance index. The integral time absolute error (ITAE) criterion is used as the performance index. The ITAE criterion is used to locally optimize the controller and to evaluate the degree to which the current set parameters satisfies the formulated objective. The ITAE criterion is represented as [15]:

$$
\operatorname{ITAE}=\int_{0}^{t_{m} a x} t .\left|e_{\omega}(t)\right| . d t
$$

where $t_{m a x}$ is the maximum time. The ITAE performance index has the advantage of producing a better optimization than the other performance indices such as the integral of the absolute error (IAE) and the integral square error (ISE) criterion. In addition, the ITAE criterion is more sensitive and it has the best selectivity.

If the speed error $\mathrm{e}_{\omega}$ in not within the specified limit, the TS-FLC block operates as follows [15]:

$$
\begin{array}{r}
\text { If }\left\{e_{r} \text { is ZERO and } d e_{r} \text { is ZERO }\right\} \\
\text { THEN }\left\{w_{e} \text { is ZERO and } w_{d e} \text { is ZERO }\right\}
\end{array}
$$

The values of $n_{e}$ and $n_{d e}$ are calculated from $w_{e}$ and $\mathrm{w}_{\mathrm{de}}$ using (13) and (14). This self tuning mechanism optimizes the proposed wavelet-fuzzy based self-tuning controller to ensure robust speed control.

The self-tuning fuzzy logic, which has been considered in this study, satisfies the specific sectorial properties of the mapping which are classified as the sectorial fuzzy control (SFC) [17]. In general, the SFC satisfies the passivity conditions and can be proven to be stable for all times [18]. The proposed wavelet fuzzy based self-tuning controller, which consists of two fuzzy blocks, satisfies the properties of the SFC and hence is can be considered as a SFC. As a result, the proposed wavelet-fuzzy based self-tuning controller is stable at all times.

\section{CONTROL AlgORITHM}

The flowchart for implementing the proposed control algorithm is shown in Fig. 7. The speed error, which is the difference between the set speed and the actual speed, is computed and is given as an input to the proposed wavelet-fuzzy based self-tuning controller. The error speed is decomposed into different frequency components using the wavelet transform.

The speed error is also given as an input to the self-tuning fuzzy logic control. The TS-FLC along with the reference model generate the weight values required for updating the scaling factors of the self-tuning fuzzy logic control. The self-tuning fuzzy logic control generates 


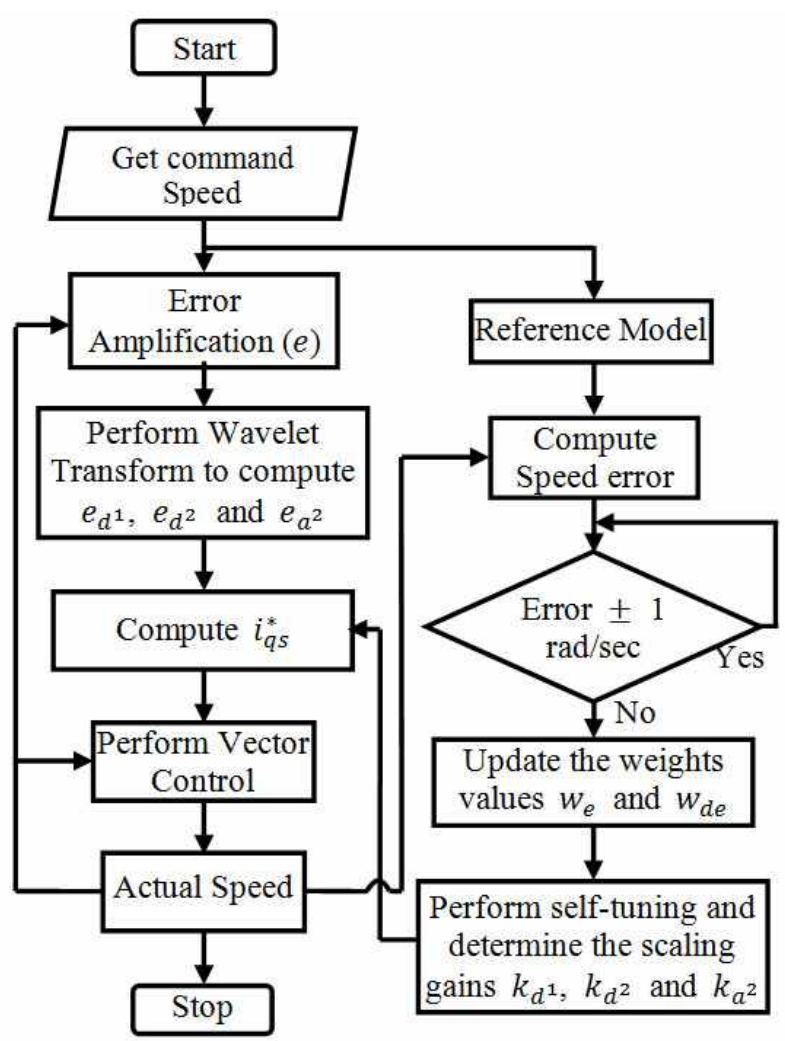

Fig. 7. Flowchart of the proposed wavelet-fuzzy based self tuning controller for Induction motor drives.

the scaling gains of the controller. The self-tuning fuzzy logic generates the optimum scaling gains for the proposed wavelet fuzzy based controller. However, the self-tuning algorithm works only if the speed error between the actual speed and the reference model speed is $\pm 1 \mathrm{rad} / \mathrm{sec}$. The scaling gains were updated online according to the self-tuning algorithm. The scaling gains are combined with the corresponding wavelet coefficients to generate the electromagnetic torque component command for the induction motor drive. The torque component command generated by the wavelet fuzzy based self-tuning controller is used to perform the indirect field oriented control of the induction motor drive.

\section{EXPERIMENTAL IMPLEMENTATION}

The hardware schematic for the real time implementation of the proposed wavelet-fuzzy based controller is shown in Fig. 8. It mainly consists of an induction motor, a control PC, a digital signal processor (DSP) board, an IGBT based SVPWM inverter and measuring instruments. The induction motor has a $2 \mathrm{hp}$ rating. The motor specifications are summarized in Table II.

The proposed wavelet fuzzy based controller has been implemented in the dSPACE ds1102 DSP controller board in

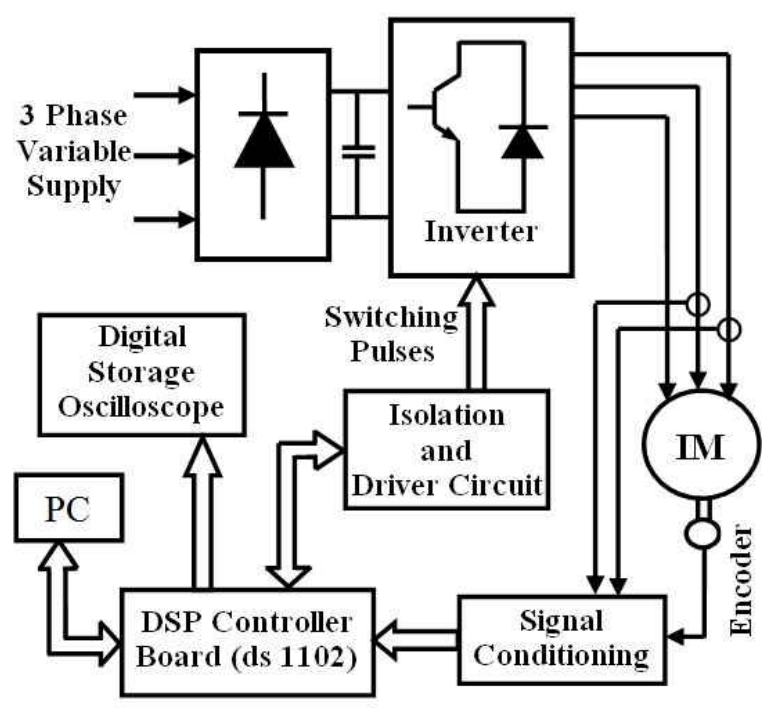

Fig. 8. Hardware Schematic for real-time implementation of the proposed wavelet-fuzzy based controller.

TABLE II

Motor SPECIFICATIONS

\begin{tabular}{|l|c|}
\hline Rated Power & $2 \mathrm{hp}$ \\
Rated Voltage & $430 \mathrm{~V}$ \\
Rated Speed & $1750 \mathrm{rpm}$ \\
Rated Frequency & $50 \mathrm{~Hz}$ \\
Number of pole-pairs & 2 \\
Stator Resistance & $3.26 \Omega$ \\
Rotor Resistance & $3.04 \Omega$ \\
Stator Inductance & $18.62 \mathrm{mH}$ \\
Rotor Inductance & $18.62 \mathrm{mH}$ \\
Motor Inertia & $0.035 \mathrm{kgm} 2$ \\
Friction factor & $0.005 \mathrm{Nms}$ \\
\hline
\end{tabular}

real time. The main processor of the DSP board is a TMS $320 \mathrm{C} 3132$ bit floating bit digital processor. The DSP board consists of all the required peripherals including an analog to digital (A/D) converter, a digital to analog (D/A) converter and incremental encoder interfaces. The dSPACE control desk software has been used to download the proposed control algorithm in the DSP board. The control desk software is also used to give the command speed to the motor.

The motor currents were measured using hall-effect sensors and are fed to the DSP board through the A/D converter. These signals were given as an input to the DSP board through the $\mathrm{A} / \mathrm{D}$ converter after proper signal conditioning. The proposed wavelet-fuzzy based speed controller is used to generate the torque command for the drive system. The digital output of the DSP control board is used as the switching pulse for the inverter. These digital signals are fed through the isolation and driving circuits, to trigger the IGBT's of the three-phase inverter. A digital storage oscilloscope with a bandwidth of $100 \mathrm{MHZ}$ and a real 

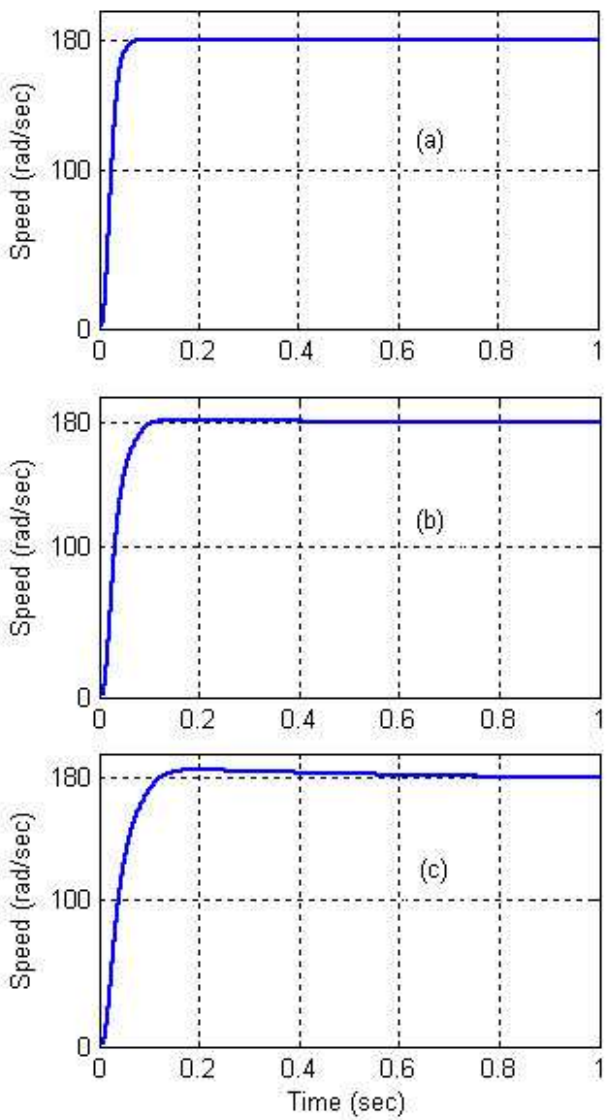

Fig. 9. Simulated statring response for a command speed of 180 $\mathrm{rad} / \mathrm{sec}$ at no load for (a) wavelet-fuzzy based controller (b) fuzzy controller and (c) PI controller.

time sampling rate of 500 mega samples per second(MS/s) is used for tracing the speed responses.

\section{RESULTS AND DISCUSSION}

The effectiveness of the proposed wavelet-fuzzy based controller for the IFOC of an induction drive is validated by simulation and experimental results under different operating conditions and load disturbances. The simulation of the proposed controller in the IFOC of an induction drive is performed using MATLAB/Simulink. The sampling time of the simulation is $2 \mu \mathrm{sec}$. The induction motor is also simulated with a conventional fixed gain PI controller and a fuzzy based controller to compare the effectiveness of the proposed controller. The fuzzy based controller for the IFOC of an induction motor is implemented using [13], [14].

Fig. 9 (a) - (c) shows the speed response of the induction motor started at no load with a command speed of 180 $\mathrm{rad} / \mathrm{sec}$. The motor follows the command speed with zero steady state error and a fast response when compared to conventional PI and fuzzy based controllers. The response of the speed control system to a step change in the set speed
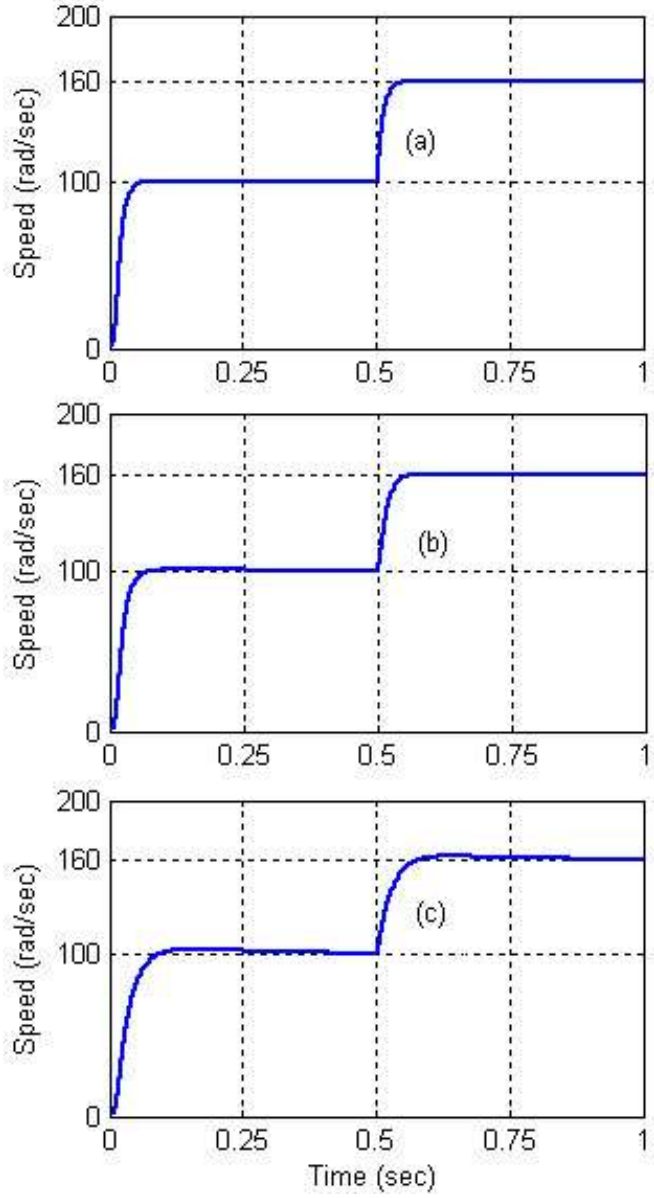

Fig. 10. Simulated speed response for a change command speed from $100 \mathrm{rad} / \mathrm{sec}$ to $160 \mathrm{rad} / \mathrm{sec}$ for (a) wavelet-fuzzy based controller (b) fuzzy controller and (c) PI controller.

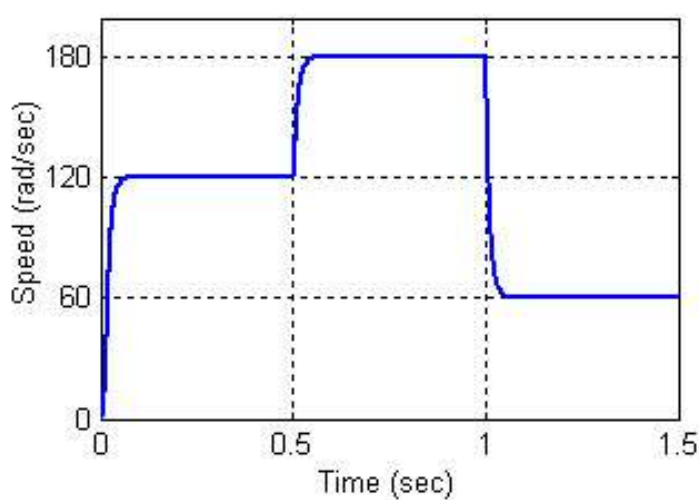

Fig. 11. Simulated speed response for increase in command speed from 120 to $180 \mathrm{rad} / \mathrm{sec}$ and again decreased to $60 \mathrm{rad} / \mathrm{sec}$ for the proposed wavelet-fuzzy based controller.

from $100 \mathrm{rad} / \mathrm{sec}$ to $160 \mathrm{rad} / \mathrm{sec}$ is investigated in Fig. 10 (a) (c) for the proposed wavelet based controller, a fuzzy based controller and a PI controller, respectively. Comparing the performances, the proposed controller shows a significant improvement in settling time. It is able to follow the set speed without an overshoot or a steady state error. Fig. 11 shows the speed response for an increase in the command speed 

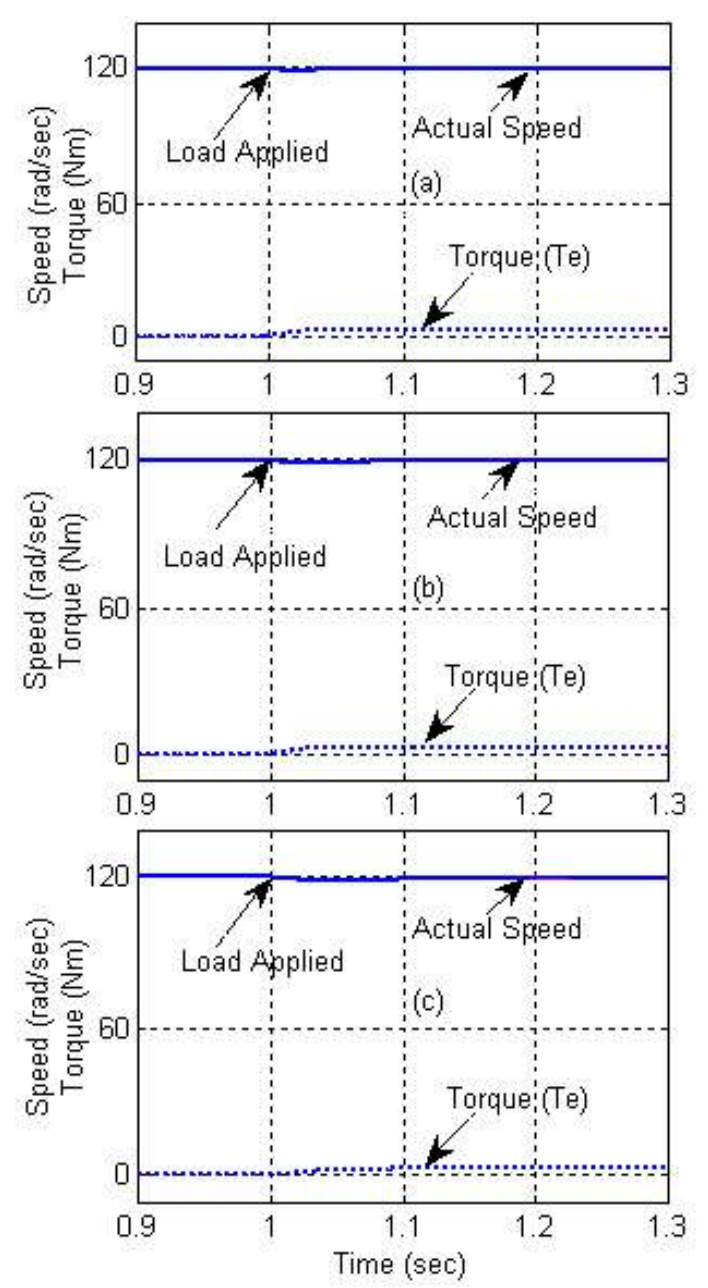

Fig. 12. Simulated speed and torque response for a step change in load from 0 to $2.5 \mathrm{Nm}$ is applied at $\mathrm{t}=0.5 \mathrm{sec}$ for (a) wavelet fuzzy based controller (b) fuzzy controller and (c) PI controller.

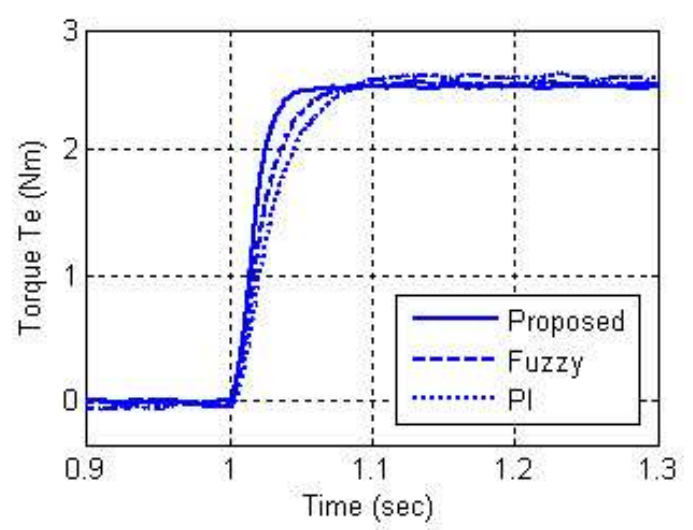

Fig. 13. Comparison of the torque response for step change in load from 0 to $2.5 \mathrm{Nm}$ at $\mathrm{t}=1 \mathrm{sec}$ for the proposed wavelet fuzzy based controller, fuzzy controller and PI controller.

form $120 \mathrm{rad} / \mathrm{sec}$ to $180 \mathrm{rad} / \mathrm{sec}$ followed by a decrease to 60 $\mathrm{rad} / \mathrm{sec}$ for the proposed wavelet fuzzy based controller.

Fig. 12 (a) - (c) shows the simulated speed and torque response when the motor is started with a command speed of
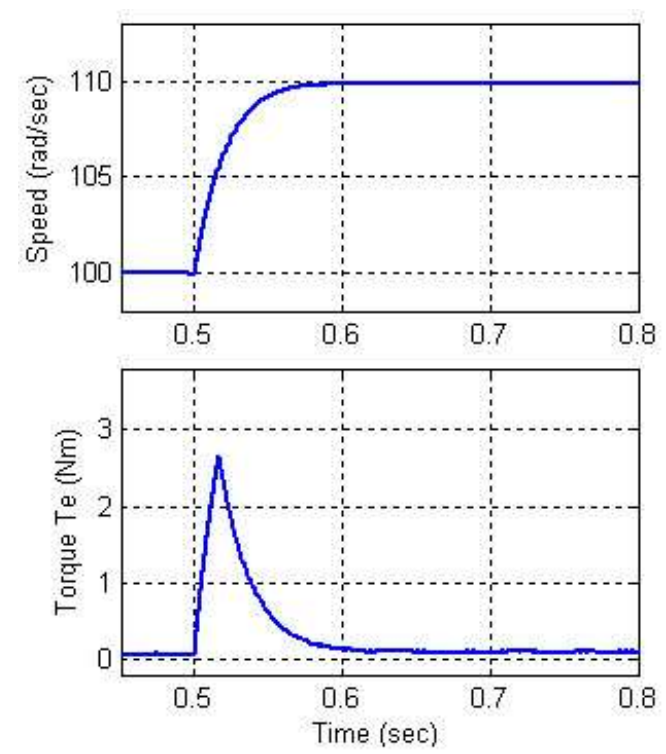

Fig.14 Simulated speed and the electromagnetic torque response of the proposed wavelet fuzzy based controller for a step speed change of $10 \mathrm{rad} / \mathrm{sec}$ at no load.

TABLE III

RSME VALUES

\begin{tabular}{|c|c|c|c|}
\hline Change in Speed & PI & Fuzzy & $\begin{array}{c}\text { Proposed } \\
\text { Wavelet Fuzzy }\end{array}$ \\
$\mathbf{0}$ to 180 rad/sec & 32.48 & 28.99 & 25.82 \\
$\mathbf{1 0 0}$ to 160 rad/sec & 16.38 & 19.56 & 18.84 \\
$\mathbf{1 8 0}$ to 60 rad/sec & 17.04 & 19.26 & 18.64 \\
\hline
\end{tabular}

$120 \mathrm{rad} / \mathrm{sec}$, and a step change in the load from 0 to $2.5 \mathrm{Nm}$ is applied at $\mathrm{t}=0.5 \mathrm{sec}$. It can be observed that the response of the proposed wavelet-fuzzy based controller is improved and better in performance when compared with the fuzzy based controller and the conventional PI controller. It is to be noted that the motor is less affected by load disturbances when compared to the conventional PI and fuzzy controllers. A comparison of the electromagnetic torque response for a step change in the load from 0 to $2.5 \mathrm{Nm}$ at $\mathrm{t}=1 \mathrm{sec}$ is shown in Fig. 13 for the proposed wavelet fuzzy based controller, the fuzzy controller and the PI controller. Fig.14 shows the speed and electromagnetic torque response of the proposed wavelet fuzzy based controller for a step speed change of $10 \mathrm{rad} / \mathrm{sec}$ at no load. The response is smooth and accurate.

The closeness between command speed and the actual speed is quantified by the root mean square error (RMSE).

The RMSE values are summarized in Table III. The RMSE results show that the proposed wavelet fuzzy based controller has a reduced RMSE under different operating conditions when compared to the conventional PI and fuzzy based controllers.

Several experiments were conducted on the hardware setup of the proposed work to evaluate the performance of the proposed wavelet fuzzy based controller. The hardware setup 

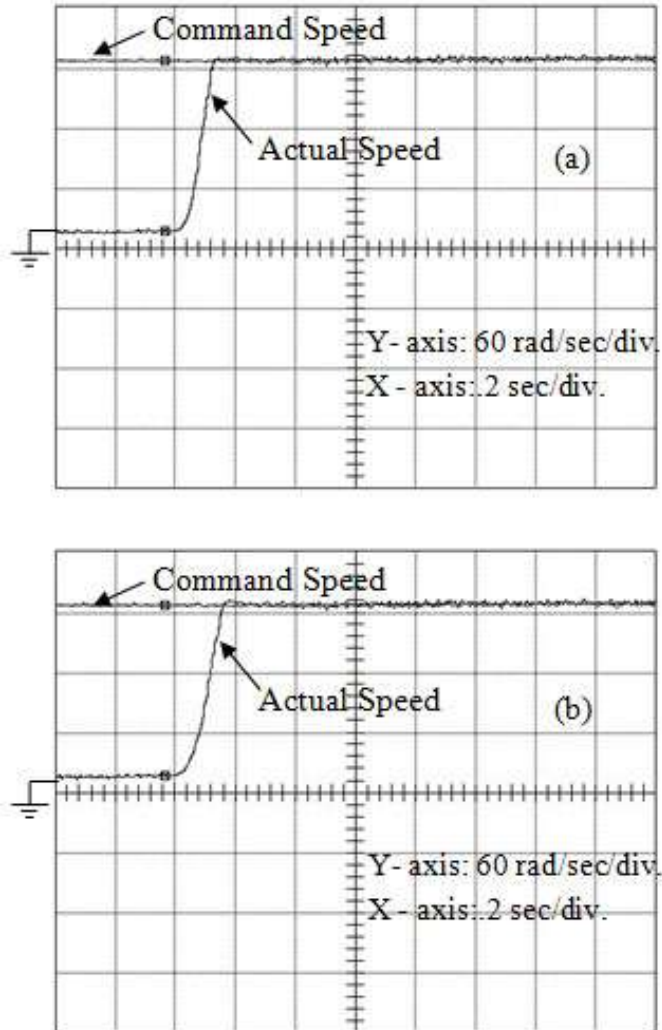

Fig. 15. Experimental starting response for a command speed of $180 \mathrm{rad} / \mathrm{sec}$ at no load for (a) wavelet fuzzy based controller and (b) PI controller.

for the IFOC of an induction motor drive was also implemented with a PI controller in order to compare its performance with that of the proposed controller. The speed responses are observed under different operating conditions and load disturbances.

Fig. 15 (a) and (b) show the experimental starting response for a command speed of $180 \mathrm{rad} / \mathrm{sec}$ for the proposed wavelet fuzzy based controller and the conventional PI controller, respectively. It can be observed that proposed wavelet fuzzy controller gives better responses in terms of overshoot, steady-state error and settling time. The experimental speed responses with a step change in speed from $120 \mathrm{rad} / \mathrm{sec}$ to $180 \mathrm{rad} / \mathrm{sec}$ followed by a decrease to $60 \mathrm{rad} / \mathrm{sec}$ are shown in Fig. 16 (a) and (b) for the proposed wavelet fuzzy based controller and the conventional PI controller, respectively. It can be seen that the proposed controller performs better for sudden changes in speed when compared to the conventional PI controller in terms of overshoot and settling time. The experimental speed response for a step change in the load from 0 to $2.5 \mathrm{Nm}$ when the motor is running with a command speed of $180 \mathrm{rad} / \mathrm{sec}$ is shown in Fig. 17 (a) and (b) for the proposed wavelet fuzzy based controller and the PI controller, respectively. The proposed controller has been found to be insensitive to load disturbances when compared to the conventional PI controller.
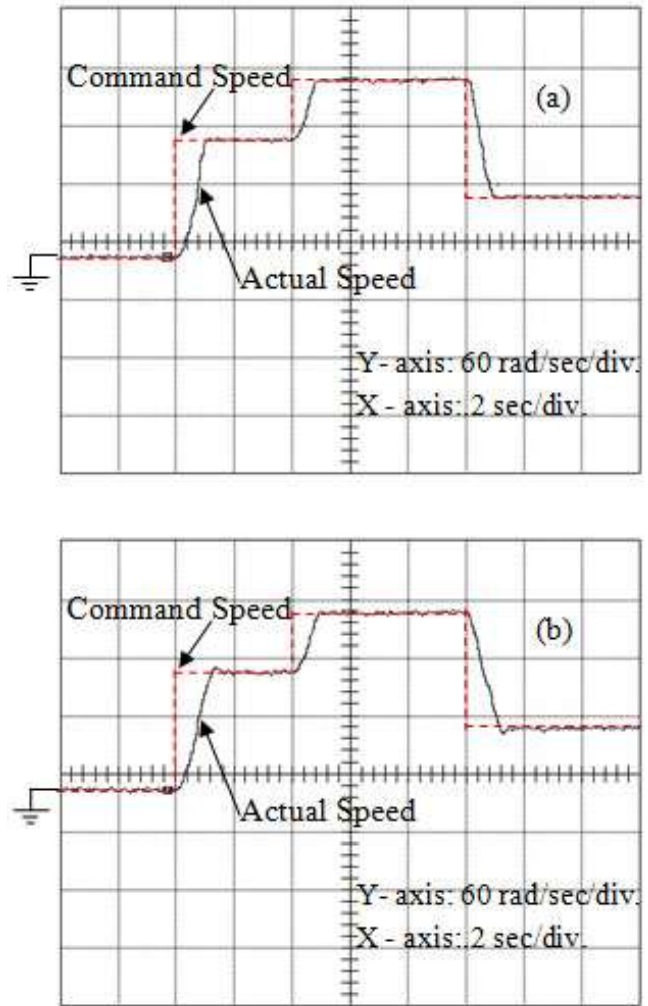

Fig. 16. Experimental speed response step change in command speed (120 rad/ sec to $180 \mathrm{rad} / \mathrm{sec}$ and again to $60 \mathrm{rad} / \mathrm{sec})$ for (a) wavelet fuzzy based controller and (b) PI controller.
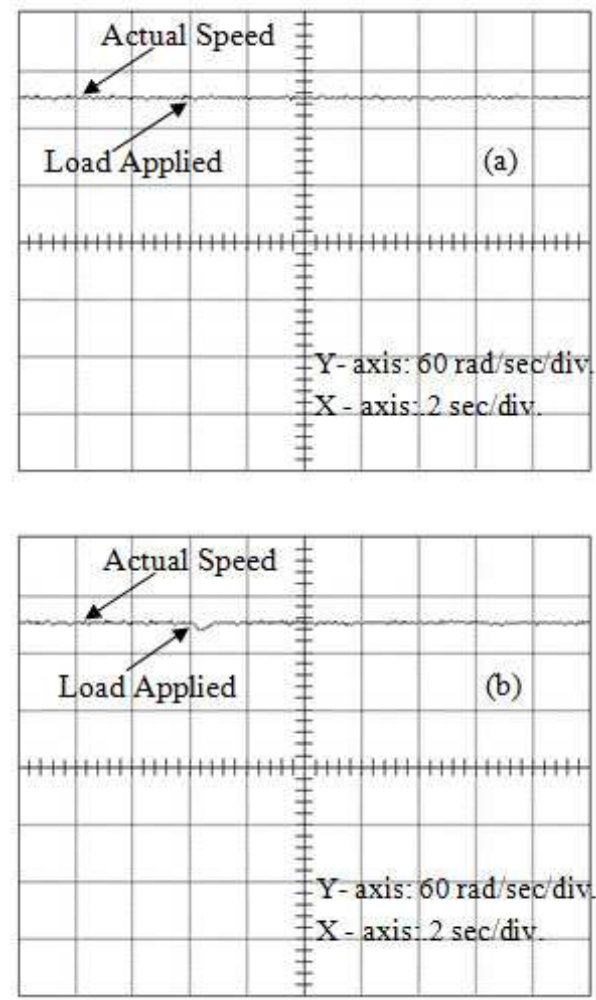

Fig. 17. Experimental speed response for a step change in load from 0 to $2.5 \mathrm{Nm}$ when the motor is running with a command speed of $180 \mathrm{rad} / \mathrm{sec}$ for (a) wavelet fuzzy based controller and (b) PI controller. 


\section{CONCLUSION}

A novel wavelet fuzzy based controller for the IFOC of an induction motor has been presented in this paper. A self-tuning algorithm is used for computing the scaling gains of the proposed controller. The complete induction motor drive including the proposed controller has been designed, simulated and successively implemented in real time using a DSP control board. The experimental and simulation results prove that the response of the proposed wavelet-fuzzy based controller is more robust when compared to the conventional PI and fuzzy based controllers in terms of its smaller overshoot, quick settling, disturbance rejection and smooth control. Possible improvements in the proposed controller will include the use of a smaller number of membership functions in the self-tuning algorithm in order to reduce the computational burden.

\section{REFERENCES}

[1] R. J. Wai, "Development of new training algorithms for neuro-wavelet systems on the robust control of induction servo motor drive," IEEE Trans. Ind. Electron., Vol. 49, No. 6, pp. 1323-1341, Dec. 2002.

[2] R. J. Wai and J. M. Chang, "Wavelet neural network control for induction motor drive using sliding mode design technique," IEEE Trans. Ind. Electron., Vol. 50, No. 4, pp. 733-748, Aug. 2003.

[3] F. J. Lin, P. H. Shen, and Y. S. Kung, "Adaptive wavelet neural network control for linear synchronous motor servo drive," IEEE Trans. Magn., Vol. 40, No. 12, pp. 4401-4412, Dec. 2005.

[4] R. J. Wai and J. M. Chang, "Intelligent control of induction servo motor drive via wavelet neural network," Electr. Power Syst. Research, Vol.61, No 1, pp. 67-76, Feb. 2002.

[5] K. Shanlin and K. Yuzhe, "Optimization design of wavelet network for estimation of flux and torque in induction motor control," in Proceeding of ICEMI, pp. 430-433, 2007.

[6] M. A. S. K. Khan and M. A. Rahman, "Implementation of a new wavelet controller for interior permanent magnet motor drives," IEEE Trans. Ind. Appl., Vol. 44, No. 6, pp. 1957-1965, Nov./Dec. 2008.

[7] M. A. S. K. Khan and M. A. Rahman, "A novel neuro wavelet based self-tuned wavelet controller for IPM motor drives," IEEE Trans. Ind. Appl., Vol. 46, No. 3, pp. 1194-1203, May/Jun. 2010.

[8] H. A. Yousef, M. E. Elkhatib, and O. A. Sebakhy, "Wavelet network-based motion control of DC motors," Expert Systems with Applicat.: An Int. Jour., Vol. 37, No. 2, pp. 1522-1527, Mar. 2010.

[9] S. Parvez and Z. Gao, "A wavelet-based multiresolution PID controller," IEEE Trans. Ind. Appl., Vol. 41, No. 2, pp. 537-543, Mar./Apr. 2005.

[10] M. Azadi, A. Rahideh, A. A. Safavi, and O. Mahdiyar, "Wavenet based vector control of a Permanent Magnet Synchronous Motor Drive," in Proceeding of IEEE EMDC, pp. 1663-1668, 2007.

[11] S. A. Saleh and M. A Rahman, "Analysis and testing of a controlled single phase wavelet modulated inverter for capacitor run induction motors," IEEE Trans. Energy
Convers., Vol. 24, No. 1, pp. 21-29, Mar. 2009.

[12] M. N. Uddin, T. S. Radwan, and A. Rahman, "Performances of fuzzy logic-based indirect vector control for induction motor drive," IEEE Trans. Ind. Appl., Vol. 38, No. 5, pp. 1219-1225, Sep./Oct. 2002.

[13] C. M. Liaw and F. J. Lin, "Position control with fuzzy adaptation for induction servomotor drive," in proceedings of IEE Electric Power Appl., pp. 397-404, 1995.

[14] E. Y. Hamid and Z. I. Kawasaki, "Wavelet based data compression of power system disturbances using the minimum description length criterion," IEEE Trans. Power Del., Vol. 17, No. 2, pp. 460-466, Apr. 2002.

[15] M. Masiala, B. Vafakhah, J. Salmon, and M. K. Andrew, "Fuzzy self-tuning speed control of an indirect field-oriented control induction motor drive," IEEE Trans. Ind. Appl., Vol. 44, No. 4, pp. 1732-1740, Nov. /Dec. 2008.

[16] L. Zhen and L. Zu, "Fuzzy learning enhanced speed control of an indirect field-oriented induction machine drive," IEEE Trans. Contr. Syst. Technol., Vol. 8, No. 2, pp. 270-278, Mar. 2000.

[17] B. Heber, L. Xu and Y. Tang, "Fuzzy logic enhanced speed control of an indirect field-oriented induction machine drive," IEEE Trans. Power Electron., Vol. 12, No. 5, pp. 772-778, Sep. 1997.

[18] G. Calcev, "Some remarks on the stability of Mamdani fuzzy control systems," IEEE Trans. Fuzzy Syst., Vol. 6, No. 3, pp. 436-442, Aug. 1998.

[19] J.L.F Daya and V. Subbiah, "A Novel Wavelet-Fuzzy based controller for robust speed control of induction motor drives", Aust. Jour. of Electr. Electron. Eng., Vol. 9, No. 2, pp. 185-195, 2012.

[20] B. K. Bose, Modern power Electronics and AC Drives, Pearson Education, 2002

[21] G. Stang and T. Nguyen, Wavelets and Wavelet Filter, Wellesly-Cambridge, 1996.

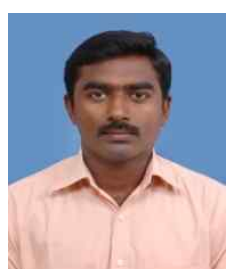

Febin Daya J. L. received his B.S. in Electrical and Electronics Engineering from Manonmaniam Sundarnar University, Tamilnadu, India, in 2002, and his M.S. in Applied Electronics from Anna University, Tamilnadu, India, in 2005. He is currently working towards his Ph.D. at Anna University. From 2005 to 2011, he was working in the Department of Electrical and Electronics Engineering at the Sri Krishna College of Engineering and Technology, Coimbatore, India. Presently he is an Assistant Professor (Sr) at VIT (Vellore Institute of Technology) University, Chennai, India. He has published or presented around 10 papers in International Journals and Conferences. Febin Daya is a Life Member of Indian Society of Technical Education. His current research interests include electrical drives, intelligent control and power electronics.

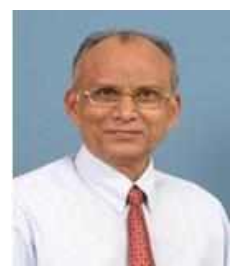

Subbiah V. obtained his B.S. in Electrical Engineering from Madras University, Tamilnadu, India, in 1965, his M.S. in Control Systems from Calcutta University, West Bengal, India, in 1968, and his Ph.D. in Power Electronics from Madras University, Tamilnadu, India, in 1981. He has been 
associated with Technical Education for more than four decades. From 1969 to 2000, he worked in various capacities at the PSG College of Technology, Coimbatore, India. In 2000, he was given a two year contract appointment with the Faculty of Engineering, Multimedia University, Malaysia. Since 2002, he has been the Dean of Electrical Sciences at the Sri Krishna College of Engineering and Technology, Coimbatore, India. $\mathrm{He}$ has published or presented around 80 papers in National and International Journals and Conferences. From 1998 to 2000 he was the Chairman of the Coimbatore Local Centre of the Institution of Engineers, India. He received the 'Outstanding Corporate Fellow Member Award 2002' from the Coimbatore Local Centre of the Institution of Engineers, India. Dr. Subbiah is a Senior Member of the IEEE, a Fellow of the Institution of Engineers, India, and a Life Member of the Indian Society for Technical Education. His current research interests include power electronics, electrical drives, power quality and renewable energy sources.

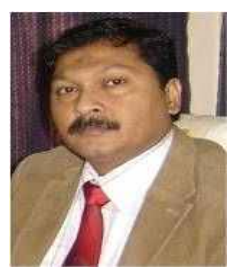

Atif Iqbal (M'09-SM'10) received his B.S. and M.S. in Electrical Engineering from the Aligarh Muslim University, Aligarh, India, in 1991 and 1996, and his Ph.D. from the Liverpool John Moores University, Liverpool, UK, in 2006. Since 1991, he has been employed as a Lecturer in the Department of Electrical Engineering, Aligarh Muslim University, where he is currently working as an Associate Professor. He is on academic assignment and working at Qatar University, Doha, Qatar. His current research interests include power electronics and multiphase machine drives. Dr. Iqbal was a recipient of the Maulana Tufail Ahmad Gold Medal for standing first in his B.S. Engineering Exams in 1991, at AMU. He also received a research fellowship from the Engineering and Physical Sciences Research Council (EPSRC), UK, for pursuing his Ph.D. studies. He has published more than 150 peer reviewed journal and conference papers. He is on the editorial board of several prestigious journals.

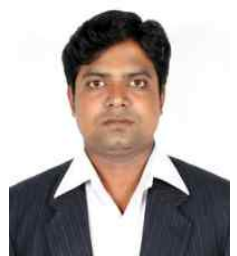

Sanjeevikumar Padmanaban received his B.S. in Electrical and Electronics Engineering from the University of Madras, Chennai, India, in 2002, his M.S. in Electrical Drives and Control from Pondicherry University, Puducherry, India, in 2006, and his Ph.D. from the University of Bologna, Bologna, Italy in 2012. From 2002 to 2007, prior to his Ph.D. studies, he worked as a Lecturer in the Department of Electrical and Electronics Engineering at the IFET College of Engineering, Tamilnadu, India. He also worked as a Training Manager at Edutech LLC, Dubai, UAE. He is currently employed as an Associate Professor in the School of Electrical Engineering at VIT (Vellore Institute of Technology) University, Chennai, India. He has published papers in National and International Conferences and Journals. His current research interests include power electronics and drives. 